\title{
A re-assessment of elemental proxies for paleoredox analysis
}

ThOMAS J. ALGEO ${ }^{1,2}$ AND JiANGSI LiU ${ }^{1,3}$

${ }^{1}$ Department of Geology, University of Cincinnati, Cincinnati, Ohio, U.S.A.

${ }^{2}$ State Key Laboratories of GPMR and BGEG, China University of Geosciences, Wuhan, China

${ }^{3}$ State Key Laboratory of Marine Environmental Science, Xiamen University, Xiamen, China

Paleoredox conditions are commonly evaluated based on elemental proxies but, despite their frequency of use, most proxies have received little comparative analysis. Here, we evaluate 21 elemental proxies, including six based on the C-S-Fe-P system (TOC, S, TOC/S, DOP ${ }_{\mathrm{T}}$, $\left.\mathrm{Fe} / \mathrm{Al}, \mathrm{C}_{\text {org }} / \mathrm{P}\right)$, nine based on trace-metal enrichment factors $\left(\mathrm{Co}_{\mathrm{EF}}, \mathrm{Cr}_{\mathrm{EF}}, \mathrm{Cu}_{\mathrm{EF}}, \mathrm{Mo}_{\mathrm{EF}}, \mathrm{Ni}_{\mathrm{EF}}, \mathrm{Pb}_{\mathrm{EF}}, \mathrm{U}_{\mathrm{EF}}, \mathrm{V}_{\mathrm{EF}}\right.$, $\left.\mathrm{Zn}_{\mathrm{EF}}\right)$, and four bimetal ratios $(\mathrm{V} / \mathrm{Cr}, \mathrm{Ni} / \mathrm{Co}, \mathrm{Ni} / \mathrm{V}$, $(\mathrm{Cu}+\mathrm{Mo}) / \mathrm{Zn})$, in 55 Phanerozoic marine units. We used principal components analysis to determine relationships among these 21 proxies in each formation and then identified patterns across the full database. The first principal component (PC1) accounted for 40.1 $\%$ of total dataset variance on average, with the highest median loadings on trace-metal enrichment factors $\left(\mathrm{Ni}_{\mathrm{EF}} 0.82, \mathrm{Mo}_{\mathrm{EF}} 0.76\right.$, all nine $\left.>0.50\right)$ and TOC (0.58). Bimetal ratios performed most poorly, yielding low median PC1 loadings (Ni/Co $0.18, \mathrm{~V} / \mathrm{Cr} 0.13$ ). The 21 elemental proxies exhibit associations linked to specific sediment host phases: (1) an organic cluster including TOC, Mo, V, and $\mathrm{Zn},(2)$ a uranium cluster including all U-based proxies, and (3) a sulfide cluster including $\mathrm{S}$ and $\mathrm{Fe}$ as well as the trace metals $\mathrm{Co}, \mathrm{Cu}$, $\mathrm{Ni}$, and $\mathrm{Pb}$.

Our findings have important ramifications for use of elemental proxies for paleoredox analysis. First, sedimentary enrichment of most proxies depends on the presence of specific mineral and organic host phases, and evaluation of elemental redox proxy data requires an understanding of elemental partitioning among host phases. Second, no single proxy is a universally reliable redox indicator, although some are more consistently useful-notably, TOC and trace-metal EFs. Third, because of this inherent variability in proxy response, adoption of redox proxy thresholds established in earlier published studies is discouraged. 